
\title{
$\begin{array}{ll}\text { Research Square } & \begin{array}{l}\text { Preprints are preliminary reports that have not undergone peer review. } \\ \text { They should not be considered conclusive, used to inform clinical practice, } \\ \text { or referenced by the media as validated information. }\end{array}\end{array}$
}

\section{An efficient virus-induced gene silencing (VIGS) system for functional genomics in Brassicas using a cabbage leaf curl virus (CaLCuV)-based vector}

\author{
Zhiliang Xiao \\ Chinese Academy of Agricultural Sciences \\ Miaomiao Xing \\ Chinese Academy of Agricultural Sciences \\ Xing Liu \\ Chinese Academy of Agricultural Sciences \\ Zhiyuan Fang \\ Chinese Academy of Agricultural Sciences \\ Limei Yang \\ Chinese Academy of Agricultural Sciences \\ Yangyong Zhang \\ Chinese Academy of Agricultural Sciences \\ Yong Wang \\ Chinese Academy of Agricultural Sciences \\ Mu Zhuang \\ Chinese Academy of Agricultural Sciences \\ Honghao Lv ( $\square$ Ivhonghao@caas.cn ) \\ Chinese Academy of Agricultural Sciences https://orcid.org/0000-0003-2635-3042
}

Research

Keywords: Cabbage, VIGS, CaLCuV, PDS, Brassicas

Posted Date: January 21st, 2020

DOI: https://doi.org/10.21203/rs.2.21427/v1

License: @ (1) This work is licensed under a Creative Commons Attribution 4.0 International License. Read Full License 


\begin{abstract}
Background: Virus-induced gene silencing (VIGS), a posttranscriptional gene silencing method, represents an effective technology for the analysis gene functions in plants. However, no VIGS vectors are available for Brassica oleracea till now. The gene silencing vectors TRV, pTYs and CaLCuV were chose to improve the VIGS system in cabbage, using phytoene desaturase (PDS) gene as an efficient visual indicator for VIGS.

Results: We successfully silenced the expression of PDS and observed the photobleaching phenomenon in cabbage by pTYs and CaLCuV, with the latter displaying higher efficiency and lower cost. Then, the factors potentially affecting the silencing efficiency of VIGS by CaLCuV in cabbage, including targeting fragment strategy, inoculation method and incubation temperature, were compared. The optimized CaLCuV-based VIGS system is as follows: approximately 500 bp insert sequence, Agrobacterium $\mathrm{OD}_{600}=1.0$, vacuum osmosis method at the bud stage, and the incubation temperature of $22{ }^{\circ} \mathrm{C}$, through which we achieved a stable silencing efficiency of $65 \%$. To further test the effectiveness of the system, we selected two other genes in cabbage including $\mathrm{Mg}$-chelatase $\mathrm{H}$ subunit (ChIH) and lobed-leaf 1 (LL1) to knock down their expression, and we observed the expected yellow or lobed leaves. In addition, we successfully applied the CaLCuV-based VIGS system in two other representative Brassica crops including B. rapa and B. nigra and thus expanded its application scope.
\end{abstract}

Conclusion: These results demonstrate that CaLCuV-based VIGS effectively work in cabbage and can be used for analyzing gene function. Our VIGS system described here will contribute to efficient functional genomics research in Brassica crops.

\title{
1. Background
}

Virus-induced gene silencing (VIGS), a posttranscriptional gene silencing method, plays a role as an antivirus defense system in plants [1-3]. When the virus with targeting fragment has successfully entered into host plant cells, it begins to replicate and transcribes its DNA or RNA genome within cells. Doublestranded RNA (dsRNA) intermediates are produced and induce the degradation of target genes. Thus, changes in plant phenotype or physiological indicators can be induced to identify gene function effectively [3]. VIGS has emerged as a widely functional genomics tool for knocking down the transcript level of genes in plants, especially in related genes of plant disease resistance, stress resistance, growth and development, and metabolic regulation [4-8]. Its advantages continue to emerge in related studies, including easy manipulation, wide application scope, yielding of fast results, high effectiveness, independence of genetic transformation, suitableness for largescale analysis of genes, and so on [7, 9-12].

In these years, various viral vectors have been successfully used in VIGS, such as tobacco mosaic virus (TMV) [13], satellite virus-induced silencing system (SVISS) [14], potato virus X (PVX) [15], barley stripe mosaic virus (BSMV) [16], Cotton leaf crumple virus (CLCrV) [17], African cassava mosaic virus (ACMV) [18], tobacco rattle virus (TRV) [19], cabbage leaf curl virus (CaLCuV) [20-21], and turnip yellow mosaic virus (TYMV) [22]. Among them, TRV has the widest host range and induces mild viral symptoms after infecting plants such as dicotyledons and monocotyledons [22, 27-32]. Each viral vector has a certain host range, and the effect of inducing silencing is different. Several species have been used to establish VIGS systems, and gene function has been successfully verified, e.g., in Arabidopsis, apple, lettuce, eggplant, tobacco, strawberry, papaya, N. benthamiana, etc [22, 27-32]. Moreover, the silencing efficiency of VIGS is influenced by many parameters, including vector targeting fragment (insertion direction and the size of the insert sequence) [18, 32], infection pattern [33-34], culture environment [35-36] and plant growth stage [37]. Therefore, more research and exploration are needed for more efficient VIGS systems.

Cabbage (Brassica oleracea L. var. capitata), an important Brassicaceae crop, is reported to be recalcitrant to transformation in many genotypes. VIGS has received recent attention because its low-cost and rapid high-throughput evaluation of gene function. VIGS systems have been established in some Brassicaceae species and play a critical role in analyzing gene function of these species. In the model plant Arabidopsis thaliana, some VIGS vectors have been successfully established and assist in gene function verification, including TRV, CaLCuV, pTYs (TYMV) [21, 37-39]. Yu et al. (2018) established an improved VIGS system based on the TYMV-derived vector that efficiently silenced the phytoene desaturase (PDS) gene in $B$. rapa through particle bombardment [23]. Zheng et al. (2010) applied the VIGS vector TRV to knock down endogenous PDS expression in three plant species ( $A$. thaliana, $B$. nigra and $N$. benthamiana) [40]. These VIGS studies set foundations for VIGS studies in cabbage and other Brassicaceaefamily crops. However, there has been no report of VIGS of cabbage and it is unknown whether any VIGS vectors can be applied to unravel gene functions in cabbage. Therefore, it is necessary to explore and develop the VIGS system in cabbage.

In this study, we tested TRV, pTYs and CaLCuV to develop VIGS systems in cabbage, using PDS gene as an efficient control for VIGS. Finally, we efficiently down-regulate the PDS in cabbage by pTYs and CaLCuV, and this latter system could also be applied to other Brassicaceae. The VIGS system will pave an important way for analyzing gene function in Brassicaceae.

\section{Materials And Methods}

\subsection{Plant materials and growth conditions}

B. oleracea accession '87-534', B. rapa cultivar 'Zhongbai 76', B. nigra accession 'Juntus' and B. campestris cultivar '49 Caixin' were provided by Institute of Vegetables and Flowers, Chinese Academy of Agricultural Sciences (IVF-CAAS). Plants were incubated in a mixture of compost: vermiculite (1:1) in a growth chamber, with a $16 \mathrm{~h}$ photoperiod and $50 \%$ relative humidity. Roots, stems and leaves with a photobleaching phenotype were harvested and stored at $-80{ }^{\circ} \mathrm{C}$ for follow-up analyses. TRV, pTYs and PCVA/PCVB vectors were kindly provided by Dr. Su Xiaomei (Shandong Academy of Agricultural Sciences, Jinan, China), Prof. Zhang Changwei (Nanjing Agricultural University, Nanjing, China) and Prof. Liu Yule (Tsinghua University, Beijing, China), respectively.

\subsection{PDS analysis in cabbage and vectors construction}

To test whether TRV, pTYs and CaLCuV could effectively down-regulate the expression of target genes in cabbage, the PDS gene which is easy to score photobleached phenotype was used as a reported gene. The sequences of BoPDS were obtained from 'T01000' Brassica reference genomes

Page 2/13 
(http://plants.ensembl.org/Brassica_oleracea/). The primers for BoPDS (PrimerPDS) were designed by Premier 5 (Premier Biosoft International, Palo Alto, CA, USA). Total RNA was extracted from the leaves of cabbage line ' $87-534$ ' using the EasyPureTM Plant RNA Kit (Vazyme, Nanjing, China). First-strand cDNA was synthesized using the PrimeScript RT Reagent Kit (Tiangen, Beijing, China). The coding sequences of BoPDS was amplified by polymerase chain reaction (PCR), the primers were shown at Table 1 . The PCR profile was as follows: $95^{\circ} \mathrm{C}$ for $3 \mathrm{~min} ; 36$ cycles of $95^{\circ} \mathrm{C}$ for $15 \mathrm{~s}, 60^{\circ} \mathrm{C}$ for $20 \mathrm{~s}$ and $72{ }^{\circ} \mathrm{C}$ for $150 \mathrm{~s}$; and a final cycle of $72{ }^{\circ} \mathrm{C}$ for $5 \mathrm{~min}$. The PCR-amplified products were checked by $1 \%$ agarose gel electrophoresis ( $\left.150 \mathrm{~V}\right)$ and were subjected to sequencing. Then, conservative regions of BoPDS were selected and constructed on VIGS vectors.

The vector construction of the three vectors was different, and the steps are detailed below. Vector construction for CaLCuV: (i) The optional 500 bp conserved sequence of BoPDS was selected. According to the restriction sites Xba1 on PCVA and homologous arms on both sides, the primers containing restriction sites and homologous arms (PCVAP500) were designed (Table 1). (ii) The target sequences were amplified using first-strand cDNA, and PCVA was digested by Xba1 (NEB, Ipswich, USA) at $37^{\circ} \mathrm{C}$ overnight. The digested PCVA and the target sequence were linked at $50{ }^{\circ} \mathrm{C}$ for 15 min by the ClonExpress Entry One Step Cloning Kit (Vazyme). (iii) The ligation mix from the previous step was transformed into competent DH5a cells (Invitrogen, Darmstadt, Germany) and plated on LB plates containing antibiotics (kanamycin at $50 \mathrm{~m} \mathrm{~g} / \mathrm{ml}$ ) at $37^{\circ} \mathrm{C}$ overnight. Single colonies were selected, shaken in liquid LB (kanamycin at $50 \mathrm{mg} / \mathrm{ml}$ ) and subjected to sequencing by specific primer primerA (for PCVA). The empty PCVA, PCAB and PCVAP500 were isolated using FastPure EndoFree Plasmid Maxi Kit (Vazyme). (iv) Likewise, the plasmid were separately transformed into Agrobacterium tumefaciens GV3101 by the freeze-thaw transformation method. Then single colonies were selected and shaken in liquid LB (kanamycin at $50 \mathrm{mg} / \mathrm{ml}$, rifampicin at $50 \mathrm{mg} / \mathrm{ml}$ ) at $28^{\circ} \mathrm{C} 48-72 \mathrm{~h}$. The bacterial fluid were subjected to sequence again by the specific primers primerA (for PCVA) and primerB (for PCVB) to ensure constructed vectors successfully transform into Agrobacterium. Glycerol stocks were prepared for long-term storage at $-70^{\circ} \mathrm{C}$ by a mixture of Agrobacterium culture: glycerol (1:3) in a $2 \mathrm{ml}$ cryotube. Vector construction for pTYs: (i) pTYs was digested with SnaBI (NEB, Ipswich, USA). An appropriate fragment of 40 nt of BoPDS was chosen and a palindromic DNA fragment of $80 \mathrm{nt}$ with the restriction sites $\mathrm{SnaBI}$ and homologous arms on both sides was produced,

(CACGGACACTTCTACCTGACTCTGACATTATTGATGCAACCATGATAGAGCTCGATCGAGCTCTATCATGGTTGCATCAATAATGTCAGAGTCAGGTAAGTTCTCGATCT) The palindromic DNA fragment was produced by the Nanjing Genscript Technology Company in Nanjing, China and linked to pTYs by the ClonExpress Entry One Step Cloning Kit (Vazyme) (pTYsBoPDS). The ligation mix was transformed into competent DH5a, isolated using FastPure EndoFree Plasmid Maxi Kit (Vazyme) and concentrated to $1 \mu \mathrm{g} / \mu \mathrm{l}$ for particle bombardment. Vector construction for TRV:(i) The same 500 bp conserved sequence was selected for TRV2, the primers containing restriction sites EcoRI and Sacl on TRV2 were designed. (ii) The target sequences were amplified using first-strand cDNA, and TRV2 was treated by restriction enzyme EcoRI and Sacl (NEB). The digested plasmids and sequences were linked by the ClonExpress Entry One Step Cloning Kit (Vazyme). (iii) Transformed in competent DH5a cells and isolated. (iv) TRV2 (empty vector control), TRV1 and TRV2P500 were separately transformed into Agrobacterium GV3101 and subjected to sequencing by the specific primers TRV1 (for TRV1) and TRV2 (for TRV2). Glycerol stocks were prepared for longterm storage at $-70^{\circ} \mathrm{C}$ by a mixture of Agrobacterium culture.

\subsection{Viral inoculation of cabbage}

For inoculation by PCVA/PCVB, the following protocol was used: (i) Recover bacteria: inoculate the PCVA, PCVAP500, PCVB with 2 ml of LB liquid (kanamycin at $50 \mathrm{mg} / \mathrm{ml}$, rifampicin at $50 \mathrm{mg} / \mathrm{ml}$ ); shake at $28^{\circ} \mathrm{C} 10-12 \mathrm{~h}$. (ii) Add 200 ul of Agrobacterium induction culture solution to $5 \mathrm{ml}$ of LB liquid (kanamycin at $50 \mathrm{mg} / \mathrm{ml}$, rifampicin at $50 \mathrm{mg} / \mathrm{ml}$ ); incubate at $28^{\circ} \mathrm{C}$ for $6-10 \mathrm{~h}$ to a final $\mathrm{OD}_{600}$ of $0.8-1.2$. (iii) Collect $2 \mathrm{ml}$ of the above bacterial liquid and centrifuge for $8 \mathrm{~min}$ at $5000 \mathrm{rpm}, 4^{\circ} \mathrm{C}$, discard the supernatant. (iv) Add $2 \mathrm{ml}$ of infection buffer ( $5 \mathrm{mg} / \mathrm{ml}$ D-glucose, $10 \mathrm{mM}$ MES, $100 \mu \mathrm{M}$ acetosyringone, $2 \mathrm{mM}$ $\mathrm{Na}_{3} \mathrm{PO}_{4} \cdot 12 \mathrm{H}_{2} \mathrm{O}_{2}$ ) to suspend the bacteria and centrifuge for $8 \mathrm{~min}$ at $5000 \mathrm{rpm}$ and $4{ }^{\circ} \mathrm{C}$, discard the supernatant. (v) Add $2 \mathrm{ml}$ of infection buffer to suspend the bacteria, place the bacterial cultures at room temperature for 3-4 h under dark conditions. (vi) Agrobacterium vacuum-infiltration at the bud stage: mix the Agrobacterium culture suspension of PCVB with PCVA or PCVAP500 at a 1:1 ratio for vacuum-infiltrating in the bud stage: soak the germinated seeds (1 cm) in the infection mixture. Place a centrifuge tube into the vacuum dryer, and evacuate the tube using a vacuum pump at -80 kPa for $10 \mathrm{~min}$; Agrobacterium syringe-infiltration at the leaf stage: infiltrate the mixture culture into the leaves of four to six leaf stage plants by a $1 \mathrm{~mL}$ syringe, with light avoidance for $24 \mathrm{~h}$. (vii) Sow the seeds in the mixture of compost: vermiculite and investigate the phenotype after 2-3 weeks.

Inoculation by pTYs: (i) Prepare gene gun bullets: $1.5 \mu$ of DNA plasmid, $1 \mu \mathrm{m}$ gold particles (Bio-Rad, Hercules, USA), $50 \mathrm{~mm}^{3}$ of $2.5 \mathrm{M} \mathrm{CaCl}_{2}$ and $20 \mathrm{~mm}^{3}$ of $0.1 \mathrm{M}$ spermidine were was added to $1.5 \mathrm{ml}$ cryotube successively on ice. (ii) The particles mixture was shaken with an oscillator for 4 min. (iii) Then centrifuge the particles mixture for $1 \mathrm{~min}$ at $15000 \mathrm{rpm}$, the particles were washed with $200 \mathrm{ul}$ absolute ethanol twice, leaving $10 \mathrm{ul}$ of particle suspension. (iv) Add the particle suspension to holder (Bio-Rad) quickly with a pipette gun. (v) Particles was implemented using a PDS 1000/He biolistic gun (Bio-Rad) at 1300 Psi according to the manufacturer's instructions. (vi) After bombardment, the plants should be placed in the dark for 1 day, and then grown in a growth chamber under $21-28^{\circ} \mathrm{C}$.

Inoculation by TRV: The same strategy as inoculation by PCVA/PCVB, except for the infection buffer (10 mM MES, $200 \mathrm{mM}$ acetosyringone, and $10 \mathrm{mM}$ $\mathrm{MgCl}_{2}$ ).

\subsection{Analysis of insert fragments and gene expression in treated plants}

Confirmation of whether the inoculated plant is infected with the virus and the virus vectors successfully silence the expression of target gene is an essential item in the VIGS experiment. In our study, to confirm whether virus vector successfully infects plants, the treated seedlings were subjected to sequence by the specific primers primerA/B (for PCVA/PCVB), CP (for pTYs), primer1/2 (for TRV1/2), respectively. Quantitative Real-Time RT-PCR (qRT-qPCR) was performed using ChamQ SYBR qPCR Master Mix (Vazyme) to confirm whether the photobleached phenomenon was induced by BoPDS. In addition, the total RNA of stems and roots were extracted to analyze gene expression of PDS in other tissues. The gene-specific primers for qRT-PCR were designed on the basis of the PDS sequences (Table. 1), and primers for B. oleracea actin (GenBank accession number XM_013731369.1) were used as controls [41]. The PCR-amplified products were checked by agarose gel electrophoresis $(150 \mathrm{~V})$. Three technical replicates were performed for each gene and three biological replicate were performed for each sample. The relative transcription levels of BoPDS were analyzed using the 2- $\triangle \triangle \mathrm{CT}$ method [42].

Page 3/13 


\subsection{Optimization of the VIGS system in cabbage}

VIGS is currently applied efficiently in many plants, successful gene-silencing technology depends upon a dynamic interaction between virus and plant, both of which can be affected by various experimental factors. To explore the efficient VIGS system in cabbage, we compared different posttreatment approaches in our study, as described next. The length of the insert sequence of PDS should be optimum at 300-800 bp [18, 31], and different lengths of the insert sequence (approximately 300 bp, 500 bp, 700 bp, 800 bp) of PDS were inserted into PCVA. Some studies have indicated that the silencing effect efficiency of reverse insertion is better than that of forward insertion, so both forward and reverse insertions are acceptable for VIGS [9]. Different infection modes and plant growth periods were used: vacuum osmosis method at the bud stage and injection during the leaf period, with different $\mathrm{OD}_{600}$ values of the Agrobacterium infection solution $\left(\mathrm{OD}_{600}=0.8,1.0,1.2,1.4\right)$. We successively cultivated plants at different temperatures $\left(18^{\circ} \mathrm{C}, 22^{\circ} \mathrm{C}, 26^{\circ} \mathrm{C}, 30^{\circ} \mathrm{C}\right)$. The number of seedlings subjected to each treatment was 20 , and each experiment was repeated three times. The infection rates (the rate of the number of infected seedlings to number inoculated) and silencing efficiency (the rate of the number of seedlings showing a silenced phenotype to number inoculated) for each experiments were calculated. Finally, we integrated the best conditions to obtain high and stable silencing efficacy.

\subsection{Verification of genes function in cabbage and application of VIGS technology in other Brassicaceae species}

To further test our VIGS system for cabbage, we chose several reported or homologous cabbage genes to verify their genetic function by VIGS. As a leafy vegetable, the leaf traits of cabbage and other Brassicaceae species have attracted much attention. The Mg-chelataseH subunit gene (ChlH) encodes a subunit of Mg-chelatase, which is involved in chlorophyll biosynthesis [13]. The homologous gene in cabbage (Bo3g009280) was blasted from the 'T01000' genome. Ni et al. (2015) indicated that the reduced transcriptional expression of lobed-leaf 1 (LL1) was the major factor contributing to leaf marginal lobe genes in B. napus in which the homologous gene of cabbage is Bo3g002560 [43]. Then, two genes were constructed for the CaLCuV-based VIGS vectors, and VIGS experiments were performed to verify these gene functions, with a PDS vector as a control. We observed whether gene silencing caused phenotypic changes and qRT-PCR was also performed to confirm whether the gene expressions of target genes were knocked down. The gene function of these genes in cabbage will be confirmed based on these expression levels and their corresponding phenotypes.

To apply this technology to other Brassicaceae species, we used the CaLCuV-based VIGS system in B. rapa and B. nigra, two other basic species in Brassicas. For related species, many genes are highly homologous. Zheng et al. (2010) reported that TRV vectors carried the tagert sequences from cabbage can silence its orthologs in related Brassica plants, such as B. nigra and A. thaliana, and even N. benthamiana [40]. This indicates that silencing vectors have certain universality in related species. Thus, we further infected other Brassicaceae species by PCVAP500/PCVB.

\section{Results}

\subsection{PDS gene analysis and vectors construction}

Based on Brassica database 'T01000', we obtained two homologous genes of PDS (Bo3g149210, Bo4g127210) and their sequences. Then the Bo3g149210, Bo4g127210 sequences of '87-534' were amplified, sequencing and alignment results showed that the second half of Bo4g127210 (1614 bp) and Bo3g149210 (1257 bp) had high similarity of '87-534' (Fig. 1A). Then, we chose parts with similar sequences between the two genes as the target sequence to ensure the silencing effect (Fig. 1B).

The approximately $500 \mathrm{bp}$ of BoPDS was amplified, then the target sequence was linked with the digested PCVA. Additionally, the same strategy was applied to $300 \mathrm{bp}, 600 \mathrm{bp}, 800 \mathrm{bp}$ sequences and $500 \mathrm{bp}$ (reverse insertion). The amplification results showed that the PCVAP500 (500 bp), PCVAPR500 (reverse insertion), PCVAP300 (300 bp), PCVAP600 (600 bp), and PCVAP800 (800 bp) vectors were accurately constructed, as shown in Fig. 2. Subsequently, constructed vectors were transformed into Agrobacterium GV3101. The constructed pTYsBoPDS was transformed into competent DH5a cells and subjected to sequencing (Fig. 2). The same 500 bp sequence was constructed for the TRV2 vector based on the construction strategy for TRV. Moreover, we also amplified the constructed vector (TRV2P500), and the results demonstrated accurate construction (Fig. 2). Our results demonstrates that we successfully completed the construction of three VIGS vectors in cabbage.

\subsection{PDS-silencing in cabbage}

After treating the seedings, the photobleaching phenomenon was observed in the leaves of cabbage treated with PCVAP500/PCVB at 15-30 days postinfiltration (dpi) (Fig. 3). As seen from the chart, the photobleaching phenotype first appeared in the second true leaf (Fig. 3B). With the growth of plants, a photobleaching phenotype occurred in newly emerging leaves at 2-4 months (Fig. 3C, 3D). The photobleaching phenotype was accompanied by leaf shrinkage, which is a typical symptom of virus infection in plants. The control plants, which were agroinfiltrated with empty PCVA/PCVB vectors only, did not show any photobleaching symptoms and obvious leaf shrinkage (Fig. 3A). However, we observed no visible photobleaching phenotype in stems and roots. The pTYsBoPDS vector was infected with a 1000/He biolistic gun. Equally, photobleaching phenotype was also observed in newly leaves at $15-30$ days postinfiltration (Fig. 3E). The photobleaching phenomenon induced by pTYsBoPDS was different from that induced by PCVAP500; the photobleaching spots were spread over the newly developed leaves, indicating that different VIGS vectors may show different silencing phenomena. However, cabbage injected with TRV2P500 did not show any photobleaching phenomenon through repeated experiments, even if we tried to adjust the system, such as using the infection buffer for PCVA/PCVB, constructing new TRV2 with other positions and lengths of BoPDS, and so on. To ensure the accuracy of our experimental process, we also constructed TRV2 with the PDS of tomato and successfully observed the photobleaching phenomenon in tomato (Fig. S1).

\subsection{Evaluation of PCVA/PCVB fragments and gene expression in infected plants}


qRT-PCR was performed to further define the silencing effect of PDS at the transcriptional expression level by VIGS. We observed that the transcripts level of BoPDS was substantially reduced in the photobleached leaves by PCVAP500/PCVB or pTYsBoPDS compared with the leaves of the control seedlings. The reduction of PDS expression by the two silencing vectors was the same, suggesting that different vectors may perform the same silencing efficiency (Fig. 4). The reduction of PDS expression in leaves was the most significant, which is consistent with the phenomenon that photobleaching is most obvious in leaves. Moreover, the reduced expression levels of BoPDS in stems and roots showed that the gene silencing can spread to the whole cabbage plant, suggesting that the VIGS system can be used to knock down all genes in cabbage plants or a gene family in multiple tissues.

Additionally, the DNA of the photobleached plants showed the presence of the PCVAP500 and PCVB bands. Equally, the pTYsBoPDS bands were detected from the photobleached plants treated by PTYSBoPDS. The result indicated that silencing of the PDS was induced by the presence of the PCVA/PCVB or PTYsBoPDS viral vector. However, the TRV1 and TRV2 bands cannot be detect from plants treated by TRV vector, suggesting that this virus vector may not be able to infect cabbage. For silent phenotypes that cannot result in visible phenotypes, the DNA assesses and qRT-PCR can be used as an important tool to confirm whether the inoculated plant could be infected and knock down expression of target genes.

\subsection{Optimal conditions for CaLCuV-based VIGS in cabbage}

After successful application of CaLCuV-based VIGS and pTYs-based VIGS in cabbage, we chose the former for further study because of its simplicity, low cost and higher silencing efficiency. Different posttreatment approaches were used to optimize the silencing system to achieve the highest silencing efficiency. For different cDNA insert lengths, the infection rates are basically the same, while the silencing rates of $300 \mathrm{bp}, 500 \mathrm{bp}, 700 \mathrm{bp}$, and $800 \mathrm{bp}$ were $15 \%, 50 \%$, $35 \%$, and $4 \%$, respectively (Fig. 5A). The results showed that the insert lengths for silence vectors does not affect infection efficiency but silence efficiency, too long or too short insert lengths will reduce the silencing efficiency and 500 bp was the optimum length for PCVA. For the forward and reverse insert directions, the silencing rates of PCVAP500 was basically the same as PCVAPR500, which indicated that the insertion direction had no effect on silencing efficiency (Fig. 5B). For different infection modes and plant growth periods, the vacuum osmosis method at the bud stage showed more advantages, including higher infection efficiency, batch production, and easy operation. The infection rates for different $\mathrm{OD}_{600}$ values and growth temperatures showed that these factors directly affect the infection process, unsuitable conditions will seriously interfere with infection process. Moreover, different $\mathrm{OD}_{600}$ values of the Agrobacterium infection solution also affected the efficiency of silencing, with high or low $\mathrm{OD}_{600}$ values reducing silencing efficiency, of which $O D_{600}=0.8-1.0$ of the Agrobacterium infection solution was remarkable in terms of silencing efficiency (Fig. $5 \mathrm{C}$ ). In addition, infected plants at $22^{\circ} \mathrm{C}$ preformed the highest rate of infection (Fig. 5D). Thus, both higher and lower growth temperatures decreased the silencing efficiency, and VIGS at high temperatures did not work. We found that high temperatures accelerated the disappearance of the photobleached phenotype. All data for infection rates and the silencing efficiency is listed at Table S1. Based on the above results, we choose optimal conditions to carry out VIGS experiments: the VIGS vector PCVAP500/PCVB; the vacuum osmosis method at the bud stage; $\mathrm{OD}_{600}=1.0$ of Agrobacterium infection; $22{ }^{\circ} \mathrm{C}$. The silencing efficiency of PDS was approximately $65 \%$, which resulted in a highly stable and efficient VIGS system in cabbage by PCVA/PCVB.

\subsection{Verification of genetic functions of BoChlH and BoLL1 in cabbage}

Based on the optimized VIGS system, the silencing vectors PCVABoChIH and PCVABoLL1 were constructed (Fig. 6A) and infected into cabbage, with a PDS gene as a control. The photobleaching phenomenon in the control indicated that our experimental operation was correct. The treated plant appeared yellowing phenotype and lobed-leaf phenotype in the newly developed leaves, respectively (Fig. 6C, 6D). Then, DNA assesses and qRT-PCR results showed that the silencing vectors PCVABoChIH and PCVABoLL1 successfully infected plant and the gene expressions were significantly reduced with the leaves (Fig. 6B). We successfully verified that BoChIH and BoLL1 are involved in chlorophyll biosynthesis and the lobed-leaf characteristic by CaLCuV-based VIGS in cabbage, and reducing gene expression in cabbage can cause corresponding phenotypic mutations.

\subsection{The CaLCuV-based VIGS system can be used in other Brassica plants}

The sequences of PDS gene in B. oleracea, B. nigra, B. rapa, B. campestris were compared, the result showed that the PDS is highly conservative in the above crops. And the silence vector PCVAP500/PCVB can be used to knock down endogenous PDS expression of these Brassicaceae. The photobleaching phenomenon was observed in these crops (Fig. 3F, 3G, 3H). The infection phenotype and duration were consistent with those of cabbage. B. rapa (AA), B. nigra (CC) and B. oleracea (BB) are the three basic species in Brassicaceae. The results indicate that the CaLCuV-based VIGS system may apply to more Brassicaceae species.

\section{Discussion}

Cabbage is an important vegetable crop due to its wide adaptability, strong resistance, healthcare-related value, and favorable taste [44]. Recently, increasing studies of important traits in cabbage have been reported, including petal color, yellow-green leaf, glossy green, hybrid lethality, Fusarium wilt and selfincompatibility [45-48]. These studies not only enrich the germplasm resources of cabbage but also promote the exploration of the molecular mechanism of cabbage. Transgenic technology and new clustered regularly interspaced short palindromic repeats (CRISPRs) has received recent attention because it is stably inherited and developed as important techniques for analyzing gene function, and several optimized transformation system in some Brassica crops have been reported [49-54]. However, low transformation efficiency and time consumption limit their effectively and widely applications. Therefore, developing a low-cost and rapid high-throughput evaluation of gene function validation in cabbage is necessary. VIGS is widely used for plant functional genomics with high efficiency and rapidity, so we attempted this technology in cabbage and finally successfully established a VIGS system in cabbage.

Currently, various viruses have been successfully applied to VIGS for unravelling gene functions. In our study, the PDS gene successfully silenced by pTYs and CaLCuV except for TRV vector, suggesting that each viral vector can only effectively silence genes of some species, even related species. pTYs-based VIGS and CaLCuV-based VIGS can achieve the same effect according to silencing phenomenon and qRT-PCR results. pTYs-based VIGS adopted particle

Page 5/13 
bombardment to transform plants, which is an expensive and complex instrument. And some degree of technical skill is required for particle bombardment. By contrast, CaLCuV-based VIGS showed simplicity, low cost and higher silencing efficiency by Agrobacterium infection, so we chose the latter for further study. And this is the first report that applies the CaLCuV vector to cabbage. CaLCuV is a member of the genus Begomovirus, family Geminiviridae, and has a broad host range [20-21, 55]. In addition, CaLCuV-based vector can use miRNAs to knock down RNA-mediated silencing of genes in Nicotiana benthamiana [21]. Morever, we successfully applied the CaLCuV-based VIGS vector to B. rapa, B. nigra and B. campestris. Our results indicate that the CaLCuV-based VIGS system may apply to more Brassicaceae species.

After obtaining the suitable virus vector, it is necessary to coordinate the dynamic balance between the replication and transmission of viruses in plant hosts and the growth and development of plants to ensure that silent signaling molecules can spread and amplify systematically in plants and to ensure the high efficiency and persistence of systematic silencing [9]. According to previous studies, the insertion fragment causing target gene silencing is 23 bp 1.5 Mb and some studies reported that 300-800 bp inserts was the optimum length for the silencing effect [19, 56-57]. In this study, the 500 bp insert sequence exhibited a higher silencing efficiency and more than 800 bp insert sequences will be of little use, causing 'Off-target Silencing'. How to effectively transfer virus vectors into plant cells is the key to the replication and transfer of viruses in plants. At present, most transformation vectors were transformed using the Agrobacterium-mediated method, including the Agrobacterium toothpick stabbing method [58], plasmid mechanical friction inoculation [59], host virus juice inoculation [60], particle bombardment [23,61], Agrobacterium infection by injection [62-64], and Agrobacterium vacuum infiltration [56]. Both infection methods successfully transferred the virus vector to the plant in my study; Agrobacterium vacuum infiltration at the bud stage can be used to carry out batch experiments and confirm the phenotype at the seedling stage. Additionally, formulation of the infection solution and concentration of the bacterial solution also affect silencing efficiency. Our results showed that Agrobacterium at $\mathrm{OD}_{600}=1.0$ used for infection had the highest silencing efficiency. Environmental factors also affect the accumulation, transmission and growth of viruses in plants. The optimum temperature for effective silencing varies with the viral vector and host plant [35]. In general, a high temperature environment can lead to a significant reduction in the viral content and gene silencing efficiency in plants. By contrary, viral content and gene silencing efficiency increased significantly at low temperature conditions. Tuttle et al. discovered that the ambient temperature needed to be lower than $21^{\circ} \mathrm{C}$ to obtain a better silencing phenotype and that TRV-mediated VIGS was almost completely inhibited when the ambient temperature was higher than $28^{\circ} \mathrm{C}$ [35]. Xu et al. (2018) tested silencing efficiency by TRV under different growth temperatures $\left(18^{\circ} \mathrm{C}, 25^{\circ} \mathrm{C}\right.$ and $30{ }^{\circ} \mathrm{C}$ ), and the speed of the response and the efficiency of infection were optimal at $25^{\circ} \mathrm{C}$ [36]. In our study, the $22^{\circ} \mathrm{C}$ is the most suitable temperature for PCVA/PVCB in cabbage, suggesting that appropriate low temperature can improve silence efficiency. In addition, we found that the silencing phenotypes of PDS genes performed not as a whole leaf but as a spot or patch of leaves, which indicated that the diffusion and proliferation of viral vectors presents inhomogeneity diffusion. According to our results, it did not affect our judgment to silencing phenotype. We found that described above silencing spots also appeared in other VIGS experiments, S. pseudocapsicum, cotton and pepper sliencing by TRV, N. benthamiana sliencing by CaLCuV, and so on [22, 35-36, 65]. And the adjustment of factors potentially affecting the silencing efficiency failed to change the situation. We guess that this situation may result from the plant's resistance to the virus.

In summary, we obtained a strong and stable silencing efficacy by CaLCuV in cabbage by testing different factors. Of course, a higher silencing efficacy may be obtained by testing more factors related to VIGS. The $65 \%$ silencing efficacy has reached the standard of popularization and application. These silencing phenotypes of ChlH and LL1 re-verified our gene silencing system. In our experiments, we chose genes related to the easy-to-observe phenotype, leaf phenotype and seedling stage phenotype. We did not develop VIGS experiments at the flowering stage or fruiting stage because of the complex phenotype and low infection efficiency of cabbage at these stages. It is gratifying to note that VIGS systems have been developed for flowers, fruit and trees [66-68]. We believe that we can gradually overcome these difficulties and widely apply VIGS in cabbage.

\section{Conclusion}

In this study, we successfully silenced the expression of PDS and observed the photobleaching phenomenon in cabbage by pTYs and CaLCuV vectors. Then, the factors potentially affecting the silencing efficiency of VIGS by CaLCuV in cabbage, and the optimized VIGS system using the CaLCuV silencing vector is as follows: approximately 500 bp insert sequence, Agrobacterium $\mathrm{OD}_{600}=1.0$, vacuum osmosis method at the bud stage, and the incubation temperature of 22 ${ }^{\circ} \mathrm{C}$, through which we achieved a stable silencing efficiency of $65 \%$. We successfully knocked down the expression of $C h I H$ and $L L 1$ and observed the expected yellow or lobed leaves. In addition, we applied the CaLCuV-based VIGS system in two other representative Brassica crops including B. rapa and B. nigra and thus expanded its application scope. Our VIGS system described here will pave an important way for efficient functional genomics research in Brassica crops.

\section{Declarations}

\section{Author contribution statement}

Z. Xiao designed and developed the VIGS experiments, wrote the manuscript. H. Lv, and M. Zhuang corrected the manuscript. M. Xing, X. Liu, Z. Fang, L. Yang, Y. Zhang and Y. Wang analyzed the data.

\section{Acknowledgements}

The work was performed at the Key Laboratory of Biology and Genetic Improvement of Horticultural Crops, Ministry of Agriculture, Beijing 100081, China.

We thank Dr. Su Xiaoming (Shandong Academy of Agricultural Sciences, Jinan, Shandong Province, China) for TRV vectors, Prof. Zhang Changwei (Nanjing Agricultural University, Nanjing, Jiangsu Province, China) for PTYs vector and Prof. Liu Yule (Tsinghua University, Beijing, China) for PCVA/PCVB vectors.

\section{Ethics approval and consent to participate}


No human subjects involved in this study.

\section{Consent for publication}

Not Applicable.

\section{Availability of data and materials}

The datasets used and/or analyzed during the current study are available from

the corresponding author on reasonable request.

\section{Competing interests}

The authors declare that there are no competing interests.

\section{Funding}

This study was supported by grants from the Key Projects of the National Key Research and Development Program of China (2016YFD0100307), the Science and Technology Innovation Program of the Chinese Academy of Agricultural Sciences (CAAS-ASTIP-IVFCAAS) and the earmarked fund for the Modern AgroIndustry Technology Research System, China (CARS-23).

\section{References}

1. Ratcliff F, Harrison BD, Baulcombe DC. A similarity between viral defense and gene silencing in plants. Science, 1997;276:1558-

2. Hamilton AJ, Baulcombe DC. A species of small antisense RNA in posttranscriptional gene silencing in plants. Science, 1999;286:950-52.

3. Godge MR, Purkayastha A, Dasgupta I, Kumar PP. Virus-induced gene silencing for functional analysis of selected genes. Plant Cell Rep, 2008;27:209-19.

4. Chen I, Chiu MH, Cheng SF, Hsu YH, Tsai CH. The glutathione transferase of Nicotiana benthamiana NbGSTU4 plays a role in regulating the early replication of bamboo mosaic virus. New Phytol, 2013;199:749-57.

5. Hsieh MH, Pan ZJ, Lai PH, Lu HC, Yeh HH, Hsu CC, Wu WL, Chung MC, Wang SS, Chen WH, Chen HH. Virus-induced gene silencing unravels multiple transcription factors involved in floral growth and development in phalaenopsis orchids. J Exp Bot, 2013;64:3869-84.

6. Hands P, Vosnakis N, Betts D, Irish VF, Drea S. Alternate transcripts of a floral developmental regulator have both distinct and redundant functions in Opium poppy. Ann Botany, 2011;107:1557-66.

7. Qu J, Guo XQ, Ci XY, Qi D, Wen FJ. Recent advances on molecular biology of potato virus $X$ and its application to gene expression vector. Virol Sin, 2003;18:87-92.

8. George GM, Bauer R, Blennow A, Kossmann J, Lloyd JR. Virus-induced multiple gene silencing to study redundant metabolic pathways in plants: Silencing the starch degradation pathway in Nicotiana benthamiana. Biotechnol J, 2012;7:884-90.

9. Burch-Smith TM, Anderson JC, Martin GB, Dinesh-Kumar SP. Applications and advantages of virus-induced gene silencing for gene function studies in plants. Plant J, 2004;39:734-46.

10. Dinesh-Kumar SP, Anandalakshmi R, Marathe R, Schiff M, Liu Y. Virus-induced gene silencing. Methods Mol Biol, 2011;236:287-94.

11. Peng Y, Cui XF, Zhou XP. Plant viruses 2 novel vectors for expressing foreign genes. J Zhejiang Uni-SC A, 2002;28:465-72.

12. Shao Y, Zhu HL, Tian HQ, Wang XG, Lin XJ, Zhu B Z, Xie YH, Luo YB. Virus-induced gene silencing in plant. Russi J Plant Physl, 2003;30:296-303.

13. Hiriart JB, Aro EM, Lehto K. Dynamics of the VIGS-mediated chimeric silencing of the Nicotiana benthamiana CHLH gene and of the tobacco mosaic virus vector. Mol Plant Microbe In, 2003:16;99-106.

14. Gosselé V, Faché I, Meulewaeter F, Cornelissen M, Metzlaff M. SVISS - a novel transient gene silencing system for gene function discovery and validation in tobacco plants. Plant J, 2010;32:859-66.

15. Faivrerampant O, Gilroy EM, Hrubikova K, Hein I, Millam S, Loake GJ, Birch P, Taylor M, Lacomme C. Potato virus X-induced gene silencing in leaves and tubers of potato. Plant Physiol, 2004;134:1308-16.

16. Holzberg S, Brosio P, Gross C, Pogue GP. Barley stripe mosaic virus-induced gene silencing in a monocot plant. Plant J, 2010;3:315-27.

17. Richard TJ, Haigler CH, Dominique R. Method: low-cost delivery of the cotton leaf crumple virus-induced gene silencing system. Plant Methods, $2012 ; 8: 27$.

18. Beyene G, Chauhan RD, Taylor NJ. A rapid virus-induced gene silencing (VIGS) method for assessing resistance and susceptibility to cassava mosaic disease. Virol J, 2017;14:47.

19. Burch-Smith TM, Schiff M, Liu Y, Dinesh-Kumar SP. Dinesh-Kumar S P. Efficient virus-induced gene silencing in Arabidopsis. Plant Physiol, 2006;142:2127.

20. Fauquet C, Fargette D, Thouvenel JC. Some aspects of the epidemiology of African cassava mosaic virus in ivory coast. Pans Pest Artic News Summ,1988;34:92-96.

21. Chen WW, Zhang Q, Kong JH, Hu F, Li B, Wu CQ, Qin C, Zhang PC, Shi NN, Hong YG. Mr VIGS: microRNA-based virus-induced gene silencing in plants. Methods Mol Biol,2015;1287:147-57.

22. Tang Y, Lai Y, Liu Y. Virus-induced gene silencing using artificial miRNAs in Nicotiana benthamiana. Methods Mol Biol, 2013;975:99-107. 
23. Yu J, Yang XD, Wang Q, Gao LW, Yang Y, Xiao D, Liu TK, Li Y, Hou XL, Zhang CW. Efficient virus-induced gene silencing in Brassica rapa using a turnip yellow mosaic virus vector. Biol Plantarum, 2018; 826-34.

24. Hidalgo OM, Bartholmes CM, Gleissberg S. Virus-induced gene silencing (VIGS) in Cysticapnos vesicaria, a zygomorphic-flowered Papaveraceae (Ranunculales basal eudicots). Ann Botany, 2012;109:911-20.

25. Zhang J, Yu DH, Zhang Y, Liu K, Xu KD, Zhang FL, Wang J, Tan GX, Nie XH, Ji QH, Zhao L, Li CW. Vacuum and co-cultivation agroinfiltration of (Germinated) seeds results in tobacco rattle virus (TRV) mediated whole-plant virus-induced gene silencing (VIGS) in Wheat and Maize. Front Plant Sci, 2017;8:393.

26. Chen JC, Jiang CZ, Gookin T, Hunter D, Clark D, Reid M. Chalcone synthase as a reporter in virus induced gene silencing studies of flower senescence. Plant Mol Biol, 2004;55:521-30.

27. Liu Y, Nakayama N, Schiff M, Litt A, Irish VF, Dinesh-Kumar SP. Virus induced gene silencing of a deficiens ortholog in Nicotiana benthamiana. Plant Mol Biol, 2004;54;701-11.

28. Manmathan H, Shaner D, Snelling J, Tisserat N, Lapitan N. Virus-induced gene silencing of Arabidopsis thaliana gene homologues in wheat identifies genes conferring improved drought tolerance. J Exp Bot, 2013;64:1381-92.

29. Navarro Gallón SM, Elejalde-Palmett C, Daudu D. Virus-induced gene silencing of the two squalene synthase isoforms of apple tree (Malus $\times$ domestica) negatively impacts phytosterol biosynthesis, plastid pigmentation and leaf growth. Planta, 2017;246:1-16.

30. Jeuken MJW, Zhang NW, McHale LK, Pelgrom K, den Boer E, Lindhout P, ichelmore RW, Visser RGF, Niks RE. Rin4 causes hybrid necrosis and race-specific resistance in an interspecific lettuce hybrid. Plant Cell, 2009;21:3368-78.

31. Zhao Z, Liu FZ, Zhang Y, Qi DX, Chen YH, Lian Y. VIGS expression vector construction and expression analyses of SMMSRA gene in eggplant. Acta Horticulturae Sinica, 2015;8:1495-504.

32. Liu E, Page JE. Optimized cDNA libraries for virus-induced gene silencing (VIGS) using tobacco rattle virus. Plant Methods, 2008;4:5.

33. Zhao Y, Mao WW, Chen YT, Wang W, Dai ZR, Dou ZC, Zhang K, Wei LZ, Li TY, Zeng BZ, Liu T, Fan YJ, Yan YJ, Li BB, Jia WS. Optimization and standardization of transient expression assays for gene functional analyses in strawberry fruits. Hortic res, 2019;6:53.

34. Fu DQ, Zhu BZ, Zhu HL, Jiang WB, Luo YB. Virus-induced gene silencing in tomato fruit. Plant J, 2005;43:299-308.

35. Tuttle JR, Idris A, Brown JK, Haigler CH, Robertson D. Geminivirus-mediated gene silencing from Cotton leaf crumple virus is enhanced by low temperature in cotton. Plant Physiol, 2008;148:41-50.

36. Xu H, Xu LF, Yang PP, Cao YW, Tang YC, He GR, Yuan SX, Ming J. Tobacco rattle virus-inducedphytoene desaturase (PDS) and Mg-chelatase $h$ subunit $(C H L H)$ gene silencing in solanum pseudocapsicum L. Peer J,2018;6:e4424.

37. Cai XZ, Xu QF, Wang CC, Zheng Z. Development of a virus-induced gene silencing system for functional analysis of the RPS2-dependent resistance signaling pathway in Arabidopsis. Plant Mol Biol, 2006;62:223-32.

38. Fernández-Calvino L, Guzmán-Benito I, Del TF, Donaire L, Castro-Sanz AB, Ruíz-Ferrer V, Llave C. Activation of senescence-associated dark-inducible (DIN) genes during infection contributes to enhanced susceptibility to plant viruses. Mol Plant Pathol, 2016;17:3-15.

39. Hericourt F, Jupin I. Infection of Arabidopsis thaliana plants by Turnip yellow mosaic virus (TYMV). Virologie, 1999;3:133-34.

40. Zheng SJ, Snoeren TA, Hogewoning SW, van Loon JJ, Dicke M. Disruption of plant carotenoid biosynthesis through virus-induced gene silencing affects oviposition behaviour of the butterfly pieris rapae. New Phytol, 2010;186:733-45.

41. Han F, Yuan K, Kong C, Zhang X, Yang YM, Zhuang M, Zhang YY, Li ZS, Fang ZY, Lv HH. Fine mapping and candidate gene identification of the genic malesterile gene $m s 3$ in cabbage 51S. Theor Appl Genetics 2018;131:2651-61.

42. Livak KJ, Schmittgen TD. Analysis of relative gene expression data using real-time quantitative PCR and the $2^{-\Delta \Delta c t}$ Methods, 2001;25:402-8.

43. Ni X, Huang J, Ali B, Zhou W, Zhao J. Genetic analysis and fine mapping of the lobed-leaf 1(BnLL 1) gene in rapeseed (Brassica napus L.). Euphytica, 2015;204:29-38.

44. Fang ZY, Sun PT, Liu YM, Wang XW, Hou AF, Bian CS. A male sterile line with dominant gene (Ms) in cabbage (Brassica oleracea var. capitata) and its utilization for hybrid seed production. Euphytica, 1997;97: 265-

45. Han FQ, Yang C, Fang ZY, Yang YM, Zhuang M, Lv HH, Liu YM, Li ZS, Liu B, Yu HL, Liu XP, Zhang YY. Inheritance and InDel markers closely linked to petal color gene (CPC-1) in Brassica oleracea. Mol Breeding, 2015;35:160.

46. Liu XP, Yang C, Han FQ, Fang ZY, Yang LM, Zhuang M, Lv HH, Liu YM, Li ZS, Zhang YY. Genetics and fine mapping of a yellow-green leaf gene (ygl-7) in cabbage (Brassica oleracea capitata L.). Mol Breeding,2016;36:82.

47. Liu X, Han FQ, Kong CC, Fang ZY, Yang LM, Zhang YY, Zhuang M, Liu YM, Li ZS, Lv HH. Rapid introgression of the fusarium wilt resistance gene into an elite cabbage line through the combined application of a microspore culture, genome background analysis, and disease resistance-specific marker assisted foreground selection. Front Plant Sci, 2017;8:354.

48. Xiao Z, Hu Y, Zhang XL, Xue YQ, Fang ZY, Yang LM, Zhang YY, Liu YM, Li ZS, Liu X, Liu ZZ, Lv HH, Zhuang M. Fine mapping and transcriptome analysis reveal candidate genes associated with hybrid lethality in cabbage (Brassica oleracea). Genes, 2017;8:2-17.

49. Thomas W, Markus N, Thomas D, Manfred K, Marco H. Efficient generation of mutations mediated by CRISPR/Cas9 in the hairy root transformation system of Brassica carinata. Plos One 2017;12:e0185429.

50. Lee MK, Kim HS, Kim JS, Kim SH, Park YD. Agrobacterium-mediated transformation system for large-scale producion of transgenic chinese cabbage (Brassica rapa ssp.pekinensis) plants for insertional mutagenesis. J Plant Biol 2004;47:300-6. 
51. Xiong XP, Liu WM, Jiang JX, Xu LA, Cao JS. Efficient genome editing of Brassica campestris based on the CRISPR/Cas9 system. Mol Genet Genomics 2019;5:1251-61.

52. Ayako O, Takumi O, Chie K, Kanako K, Mizue I, Jun I, Nobuya K. CRISPR/Cas9-mediated genome editing of the fatty acid desaturase 2 gene in Brassica napus. Plant Physiol Bioc 2018;131:63-69.

53. Lawrenson T, Shorinola 0, Stacey N. Induction of targeted, heritable mutations in barley and Brassica oleracea using RNA-guided Cas 9 nuclease. Genome Biol 2015;16:258.

54. Chen G, Zeng F, Wang J, Wang J, Ye X, Zhu S, Yuan L, Hou J Wang C. Transgenic Wucai (Brassica campestris) produced via Agrobacterium-mediated anther transformation in planta. Plant Cell Rep 2019;38:577-586.

55. Nooduan M, Christophe B, Herve V, Dominique R. Geminivirus VIGS of endogenous genes requires SGS2/SDE1 and SGS3 and defines a new branch in the genetic pathway for silencing in plants. Plant J 2004;38:1004-1014.

56. Lacomme C, Hrubikova K, Heinl. Enhancement of virus-induced gene silencing through viral-based production of inverted- Plant J, 2003;34:543-53.

57. Thomas CL, Jones L, Baulcombe DC, Maule AJ. Size constraints for targeting post-transcriptional gene silencing and for RNA-directed methylation in Nicotiana benthamiana using a potato virus $X$ vector. Plant J, 2010;25:417-25.

58. Naylor M, Reeves J, Cooper JI, Edwards ML, Wang H. Construction and properties of a gene-silencing vector based on poplar mosaic virus (genus carlavirus). J Virol Methods, 2005;124:27-36.

59. Igarashi A, Yamagata K, Sugai T, Takahashi Y, Sugawara E, Tamura A, Yaegashi H, Yamagishi N, Takahashi T, Isogai M, Takahashi H, Yoshikawa N. Apple latent spherical virus vectors for reliable and effective virus-induced gene silencing among a broad range of plants including tobacco, tomato, Arabidopsis thaliana, cucurbits, and legumes. Virology, 2009;386:407-16.

60. Fofana IBF, Abdourahamane Sangaré, Collier R, Taylor C, Fauquet CM. A geminivirus-induced gene silencing system for gene function validation in cassava. Plant Mol Biol, 2014;56:613-24.

61. Jeyabharathy C, Shakila H, Usha R. Development of a VIGS vector based on the $\beta$-satellite DNA associated with bhendi yellow vein mosaic virus. Virus Res, 2015;195:73-8.

62. Pandey P, Choudhury NR, Mukherjee SK. A geminiviral amplicon (VA) derived from tomato leaf curl virus (TOLCY) can replicate in a wide variety of plant species and also acts as a VIGS vector. Virol J, 2009;6: 152.

63. Kang L, Udayakumar M, Mysore KS. A systematic study to determine the extent of gene silencing in Nicotiana benthamiana and other solanaceae species when heterologous gene sequences are used for virus-induced gene silencing. New Phytol, 2010;176:782-91.

64. Szittya G, Dániel S, Attila M, Zoltán H, Agnes L, Lóránt L, ZsófiaBá, József B. Low temperature inhibits RNA silencing-mediated defence by the control of siRNA generation. Embo J, 2003;22:633-40.

65. Kim J, Park M, Jeong ES, Lee JM, Choi D. Harnessing anthocyanin-rich fruit: a visible reporter for tracing virus-induced gene silencing in pepper fruit. Plant methods 2017;13:3.

66. Spitzerrimon B, Cna'Ani A, Vainstein A. Virus-aided gene expression and silencing using TRV for functional analysis of floral scent-related genes. Methods Mol Biol, 2013;975;139-148.

67. Fernandez-Moreno JP, Orzaez D, Granell A. VIGS: a tool to study fruit development in solanum lycopersicum. Methods Mol Biol, 2013;975:183.

68. Sasaki, S., Yamagishi, N., \& Yoshikawa N. Efficient virus-induced gene silencing in apple, pear and Japanese pear using apple latent spherical virus vectors. Plant Methods, 2011;7:15.

\section{Table}

Table 1. List of primer sequences used in this study 
List of primer sequences used in this study

\begin{tabular}{|c|c|c|}
\hline Primer name & Forward Primer 1 'to 3'ㅁ & Reverse Primer $\square$ 'to 5 ' $\square$ \\
\hline PrimePDS1 & ATGGCGGTTTCCGGCGATTCT & TTATGTTGATAGAGTCGCCTC \\
\hline PrimerPDS2 & ATGGGACACAACAGCTTCAGAAT & TCATGTTGATACAGTTGTCTCCG \\
\hline PCVAP500 & GCTCAGATCTGGATCCTCTATAAGACAAGAACAAGGCGAAGG & GCGGTACCCTCGAGTCTAGATCAAAATTGCCCAAATACCG \\
\hline PCVAPR500 & GCTCAGATCTGGATCCTCTATACGGTATTTGGGCAATTTTGA & GCGGTACCCTCGAGTCTAGACCTTCGCCTTGTTCTTGTCT \\
\hline PCVAP300 & GCTCAGATCTGGATCCTCTATATGGAGAAGTTAGTTGGTGT & GCGGTACCCTCGAGTCTAGAGCGATTTCGTCAGGGAAGAG \\
\hline PCVAP600 & GCTCAGATCTGGATCCTCTATATACATATATTTTTCGGTGCTT & GCGGTACCCTCGAGTCTAGATATACATATATTTTTCGGTGCTT \\
\hline PCVAP800 & GCTCAGATCTGGATCCTCTATATGTCATTGCTGGTGCTGGGTT & GCGGTACCCTCGAGTCTAGAGCGTCTCCTTGGATAGTGGTC \\
\hline PCVAChlH & GCTCAGATCTGGATCCTCTATATCTTGTGGGAGTACCGCTGGTGT & GCGGTACCCTCGAGTCTAGATGCGTAAGGAGTGAGGCTCTGGT \\
\hline PCVALL1 & GCTCAGATCTGGATCCTCTATATCTCAAATCCCGAACCAATT & GCGGTACCCTCGAGTCTAGATTAGCCCCAGAAGCTCCATG \\
\hline TRV2P500 & TCTCTTCACAAGCGCTTAAGACAAGAACAAGGCGAAGG & TGTCAGCATCTCGTTGTTTCTCAAAATTGCCCAAATACCG \\
\hline primerA & GTGCGCTGTGGGCCTATATAA & CCAAGTCTGGACGACTTCGAT \\
\hline primerB & AAAGGAGGAAGAGAGAAAATC & AGGTAAATACAAATAAGCGAT \\
\hline primer1 & TTGATTGGAAGAAGGCACAGAG & ATTTGAATGAACCCAGGCGTAT \\
\hline primer2 & TAGATAATGGTTTGGTGGTC & TAGTTTAATGTCTTCGGGAC \\
\hline $\mathrm{CP}$ & TССССТТСССАССТTСТАССG & GTGTGGGGACAGACCTCGCTAACT \\
\hline actin & CCAGAGGTCTTGTTCCAGCCATC & GTTCCACCACTGAGCACAATGTTAC \\
\hline RTBoPDS & GCCTTCTTAGATGGTAATCCTCC & СATCCTCCAGTTCAATCTTCCT \\
\hline RTBoCHlH & GACAGACGGAGTGTTGATGGC & GGGAATGGTAGCGGGAGTAAA \\
\hline RTBoL1 & ACACTTTCATGGCTCTATCG & AAATCTCACTTGGTGGCTTC \\
\hline
\end{tabular}

\section{Figures}

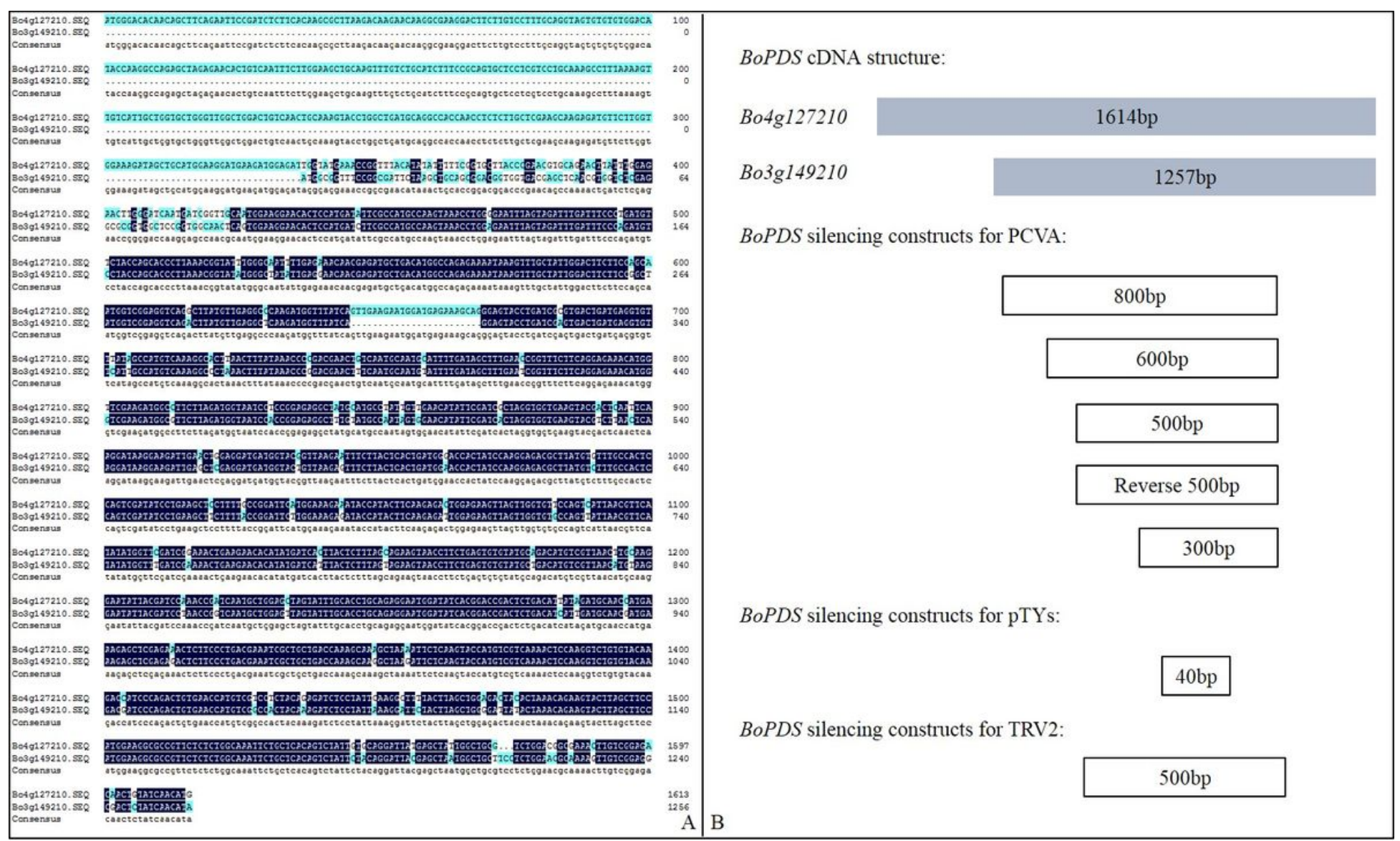

Figure 1

The alignment of BoPDS (Bo3g149210 and Bo4g127210) and position and length of BoPDS cDNA fragments used for silencing relative to the full-length CDS A, The alignment of Bo3g149210 and Bo4g127210, second half Bo4g127210 (1614 bp) and Bo3g149210 (1257 bp) had high similarity; B, Position and length of BoPDS CDS fragments used for inserting three silencing vectors. 


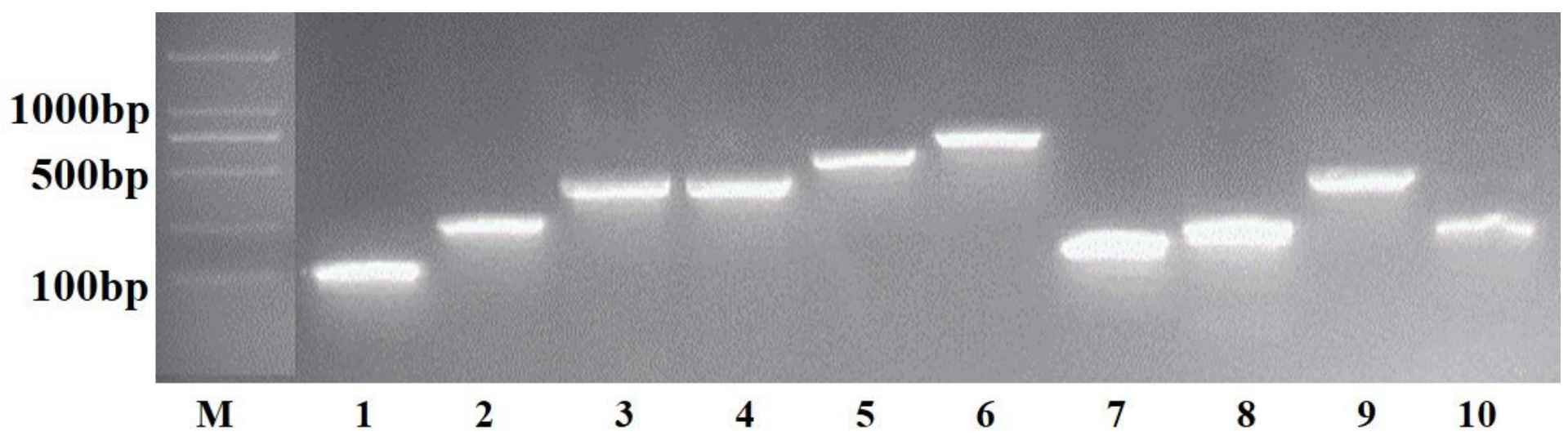

Figure 2

Detection of empty and constructed silencing vectors

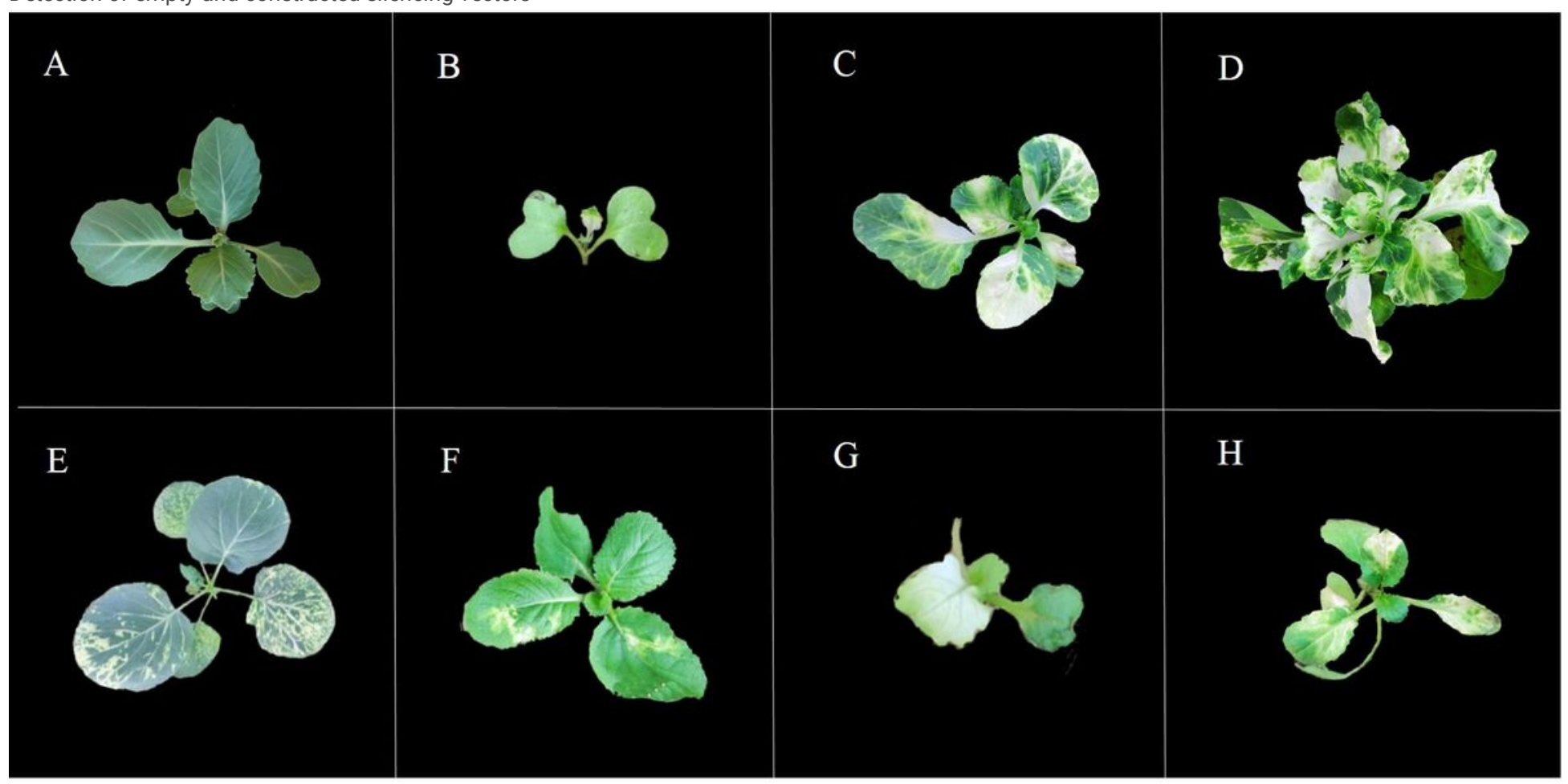

Figure 3

Silencing of PDS using CaLCuV and PTYs-based VIGS in cabbage and silencing of PDS using CaLCuV-based VIGS in B. nigra, B. rapa and B. campestris A, Plants were agro-drenched with empty PCVA/PCVB vectors (control); B, C, D, Photobleaching phenotype first appeared in the second true leaf by CaLCuVbased VIGS in cabbage, 2-4 months after infection, respectively; $E$, The photobleaching phenotype of cabbage using pTYs-based VIGS in cabbage; F, G, H, The photobleaching phenotype of B. rapa, B. nigra and B. campestris using CaLCuV-based VIGS. 


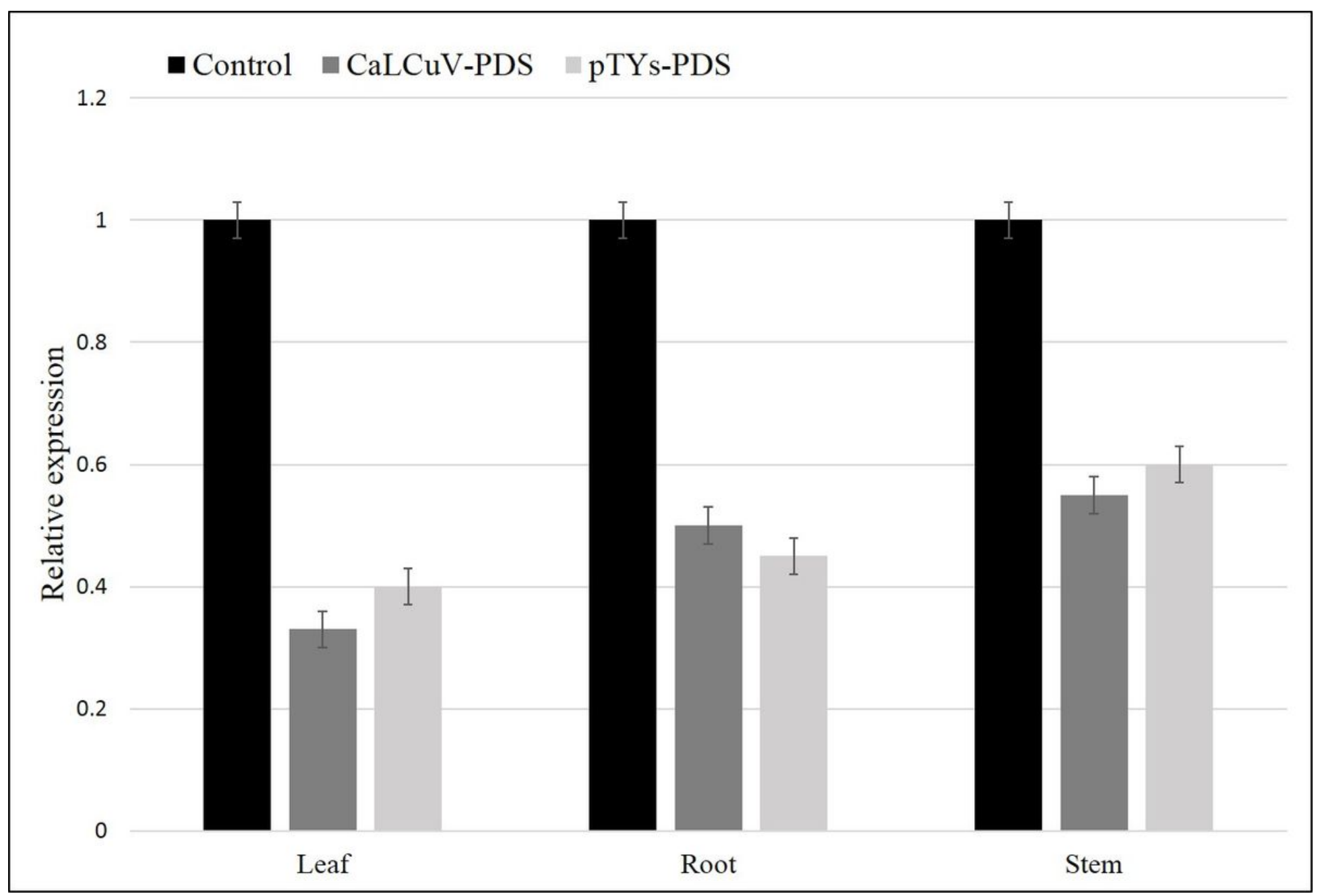

Figure 4

qRT-PCR analysis of PDS in various tissues of cabbage inoculated with CaLCuV and pTYs

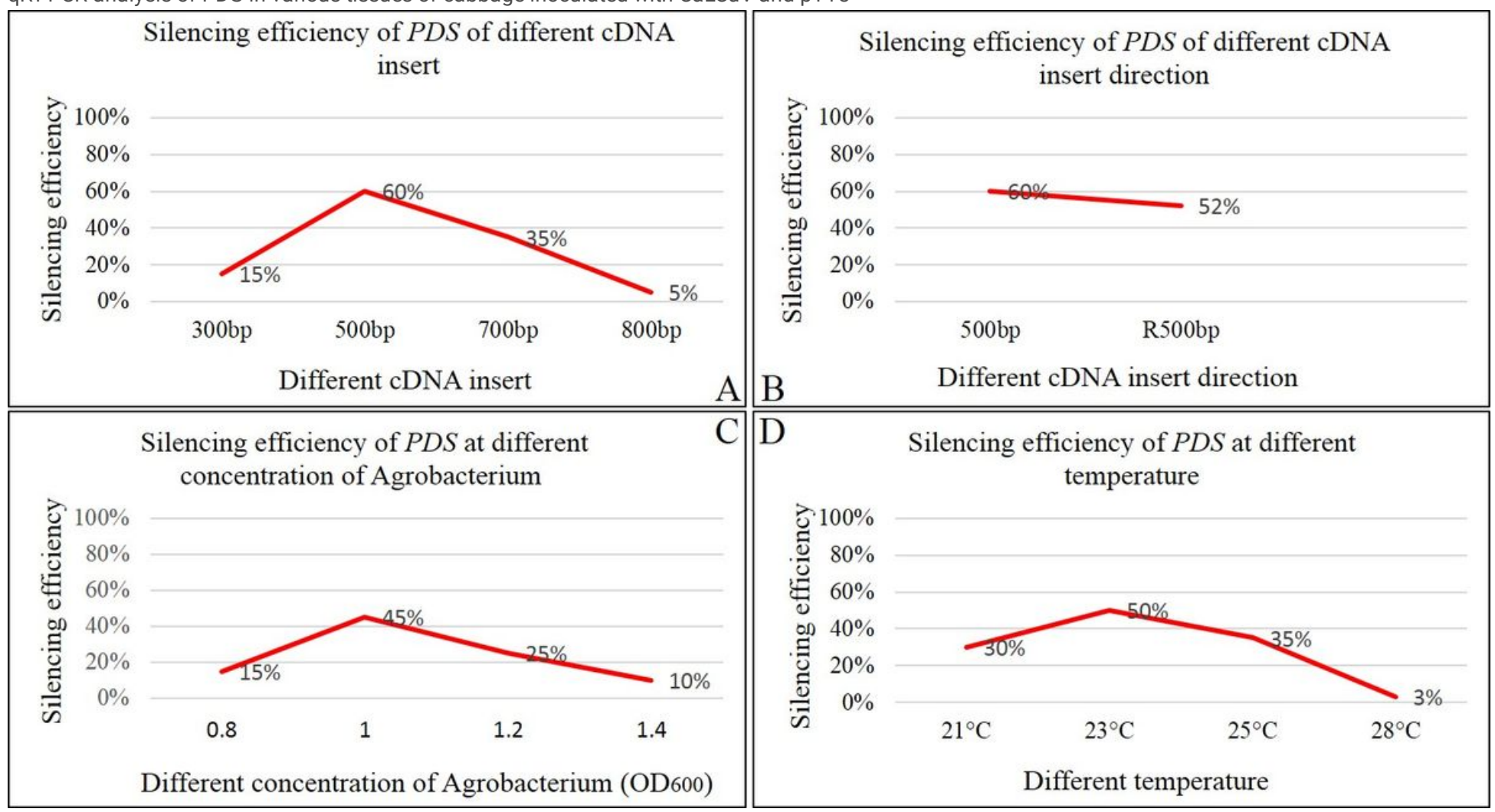


Figure 5

Silencing efficiency using different post-treatment approaches A, Silencing efficiency of PDS of different cDNA inserts; B, Silencing efficiency of PDS of different cDNA insert direction; C, Silencing efficiency of PDS at different concentration of Agrobacterium; D, Silencing efficiency of PDS at different temperatures.

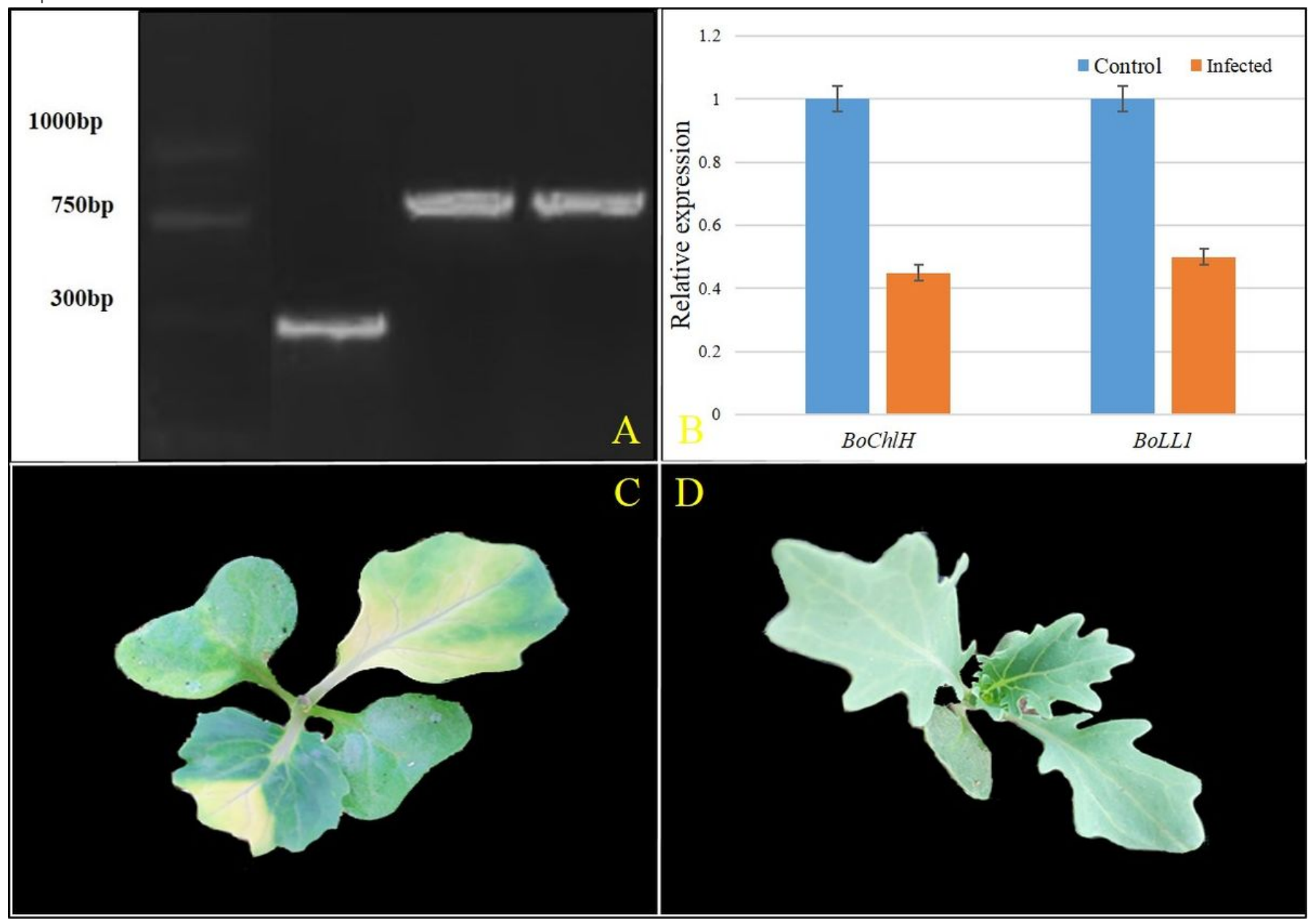

Figure 6

Detection of empty and constructed silencing vectors for BoChlH and BoLL1, its expression after infection and silence phenotype A, Empty vector and constructed silence vector, lane 1, empty PCVA vector; lane 2, PCVAChLH; Lane 3, PCVALL1; B, Expression analysis of these genes by RT-PCR after infection; C, Silencing phenotype of these genes.

\section{Supplementary Files}

This is a list of supplementary files associated with this preprint. Click to download.

- Table.S1.xlsx

- Fig.S1.jpg 